\title{
Diagnóstico de fibromatosis colli por punção aspirativa por agulha fina: relato de três casos
}

\author{
Diagnosis of fibromatosis colli by fine-needle aspiration cytology: report of three cases
}

Gisele Alborghetti Nai'; Marcelo Bastos del Hoyo²

\begin{tabular}{l}
\multicolumn{1}{c|}{ Unitermos } \\
Fibromatose \\
Fibromatosis colli \\
Punção aspirativa por agulha fina
\end{tabular}

Punção aspirativa por agulha fina

\section{resumo}

Fibromatosis colli é uma patologia benigna, rara, que se apresenta como uma massa cervical, aparecendo durante as primeiras semanas de vida e freqüentemente associada a torcicolo congênito. É uma lesão fibroblástica que acomete o músculo esternocleidomastóideo, com medidas variando entre 1 e $3 \mathrm{~cm}$. Relatamos os casos de três lactentes, dois do sexo masculino e um do feminino, de 30 dias de vida, que apresentavam massa cervical à direita, na projeção do músculo esternocleidomastóideo, medindo, cada, $1,5 \mathrm{~cm}$ no maior eixo. Foram realizadas punções aspirativas por agulha fina (PAAF), cujos esfregaços mostraram moderado número de fibroblastos isolados e também células multinucleadas, compatíveis com células musculares degeneradas. Nenhum dos casos apresentou processo inflamatório. Os achados citológicos associados ao quadro clínico permitem diagnóstico definitivo e acurado desta patologia, evitando-se uma biópsia cirúrgica, além de proporcionar um início precoce do tratamento conservador que levará à resolução da doença na maioria dos casos.

Fibromatosis colli is a benign and rare disorder presented as a neck mass, appearing during the first weeks of life and it is often associated with congenital torticollis. It is a fibroblastic lesion that affects the sternocleidomastoid muscle, and varies in size from 1 to $3 \mathrm{~cm}$. We report three cases of neonates, two males and one female, 30 days-old, presenting a right cervical mass, in the sternocleidomastoid, measuaring $1,5 \mathrm{~cm}$ each one. The major cytologic finding was loose benign fibroblasts and multinucleated cells consistent with degerating skeletal muscle fibers. None of the cases presented inflammatory cells. The cytological findings together with the clinical picture allow a definitive and accurate diagnosis of this entity, avoiding surgical biopsy, providing early initiation of conservative treatment, which will lead to resolution of the disease in the majority of the cases.

\section{Introdução}

As fibromatoses formam um espectro de entidades clinicopatológicas caracterizado por uma proliferação infiltrativa de fibroblastos que não apresentam características citológicas malignas ${ }^{(7)}$.

A fibromatosis colli (FC) tem sido reconhecida como um crescimento fibroso peculiar do músculo esterno- cleidomastóideo que geralmente aparece em neonatos. De acordo com alguns autores, um diagnóstico acurado pode ser realizado por punção aspirativa por agulha fina (PAAF).

Relatamos três casos de fibromatosis colli diagnosticados por PAAF e realizamos revisão da literatura.

1. Médica patologista; professora-assistente do Departamento de Patologia da Faculdade de Medicina da Universidade do Oeste Paulista (UNOESTE).

2. Médico cirurgião-pediátrico; professor-assistente do Departamento de Cirurgia da Faculdade de Medicina da UNOESTE.

Trabalho apresentado no XVII Congresso Brasileiro de Citopatologia. 


\section{Relato dos casos}

Três lactentes, dois do sexo masculino e um do feminino, de 30 dias de vida, apresentando massa cervical à direita, endurecida, na porção inferior do músculo esternocleidomastóideo, medindo, cada, $1,5 \mathrm{~cm}$ no maior eixo, com mobilidade horizontal, com discreto desvio cervical ipsilateral.

\section{Exame anatomopatológico}

As PAAF foram realizadas com agulhas de 22 gauges $e$ seringas de $10 \mathrm{ml}$ acopladas a um citoaspirador, obtendo-se esfregaços que foram secos ao ar e posteriormente corados pelo método de Giemsa.

O exame citológico de todos os casos mostrou moderado número de fibroblastos isolados, com núcleos ovalados e uniformes, e células multinucleadas com citoplasma amplo, compatíveis com células musculares degeneradas, em meio a fundo limpo (Figuras 1 e 2). Não se observaram componente inflamatório, atipias celulares ou figuras de mitoses.

\section{Discussão}

Em recém-nascidos, lactentes e crianças, massas cervicais se originam de uma variedade de condições patológicas, congênitas e de desenvolvimento, sendo importante distinguir lesões benignas de lesões mais $\operatorname{graves}^{(2)}$.

A FC, também conhecida como tumor esternocleidomastóideo da infância, é uma lesão benigna de células fusiformes do músculo esternocleidomastóideo. Geralmente observada nas primeiras semanas de vida, é a causa mais comum de massas cervicais no período neonatal ${ }^{(9)}$ e de torcicolo congênito muscular, representando $10 \%$ a $20 \%$ dos casos deste $\mathrm{e}^{(1,8)}$.

Esta patologia ocorre em $0,4 \%$ dos recém-nascidos ${ }^{(4,8)}$. Caracteristicamente se manifesta entre a segunda e quarta semanas de vida, como uma massa firme na porção inferior do músculo esternocleidomastóideo, especialmente na sua porção esternal ou clavicular. Entretanto têm sido relatados casos nas porções média e superior deste músculo $^{(6)}$. Freqüentemente acomete mais o lado direito que o esquerdo. Raramente é bilateral, sendo mais comum em meninos do que em meninas. Em nossos casos, os pacientes eram, em sua maioria, do sexo masculino e apresentavam comprometimento da porção inferior do músculo esternocleidomastóideo direito.

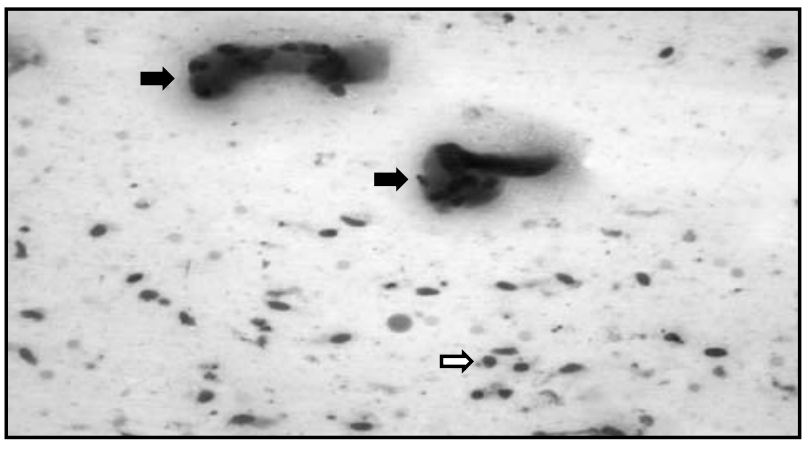

Figura 1 - Esfregaço citológico mostrando moderado número de fibroblastos isolados (seta branca) e duas células musculares degeneradas (setas pretas) (Giemsa, 100x)

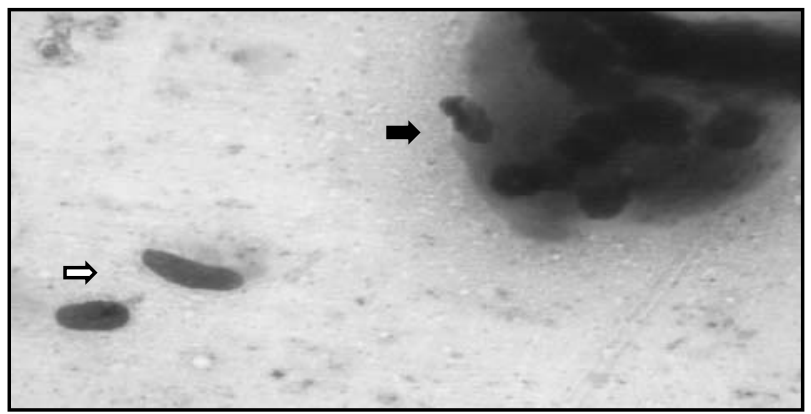

Figura 2 - Detalhe mostrando fibroblastos com núcleos ovalados e volumosos (seta branca) e célula muscular multinucleada, com citoplasma amplo (seta preta) (Giemsa, 400x)

Após o aparecimento, a massa cresce rapidamente, mas algumas semanas ou meses depois o crescimento diminui e se torna estacionário, sendo que $90 \%$ dos pacientes terão um bom prognóstico, principalmente se a terapia for iniciada e continuada por um período de tempo apropriado.

As causas deste crescimento têm sido assunto de numerosos debates na literatura. Complicações ou lesões durante o parto podem ter importância na patogenia por poderem levar a estiramento do músculo esternocleidomastóideo, com subseqüentes hemorragia, hematoma, fibrose e contratura. Insuficiência vascular resultante de isquemia ou estase venosa prolongada e/ou estiramento muscular durante o trabalho de parto parecem ser as causas mais relevantes. Fatores genéticos têm sido sugeridos devido a exemplos de aumento de incidência familiar e por associação deste crescimento com determinadas malformações ${ }^{(3,8)}$.

Embora a FC possa levar a torcicolo congênito muscular, necessitando de intervenção cirúrgica, o tratamento inicial é conservador ${ }^{(9)}$.

A PAAF é amplamente usada para avaliação de massas de cabeça e pescoço em adultos, mas também proporciona 
excelente avaliação, minimamente invasiva, de crianças com massas cervicais ou torcicolos ${ }^{(3)}$.

A literatura mostra relatos de 56 casos de PAAF de FC, onde se observam quantidade variada de fibroblastos, isolados ou agrupados, com núcleos reativos, volumosos, ovalados e uniformes entre si, células musculares degeneradas, com citoplasma amplo e multinucleação ${ }^{(3,5,8,10)} \mathrm{e}$ material granular, róseo de fundo ${ }^{(6,8)}$.

O diagnóstico clínico diferencial de massas cervicais nesta faixa etária inclui neoplasias malignas, como neuroblastoma, linfoma e rabdomiossarcoma, devendo ser rapidamente diagnosticadas. Estas apresentam achados citológicos característicos dos tumores de células pequenas da infância, como hipercelularidade, núcleos pequenos, redondos e azuis e escasso citoplasma, sendo facilmente diferenciadas da $\mathrm{FC}^{(3)}$.
O diagnóstico diferencial citológico da FC é a fibrose aponeurótica calcificante, que difere clinicamente da FC por ocorrer em indivíduos mais velhos, apresentar comprometimento de mãos e pés, além de evidência radiológica das calcificações. A fibromatose infantil é um processo mais infiltrativo, não restrita somente a um grupo muscular pequeno, sendo o diagnóstico diferencial entre as duas possível, clínica ou radiologicamente ${ }^{(3,8)}$.

A PAAF proporciona um diagnóstico acurado e rápido de massas cervicais de crianças com suspeita de FC, evitando-se as despesas e os riscos de um procedimento cirúrgico, além de proporcionar um início precoce do tratamento conservador que levará à resolução da doença na maioria dos casos.

Após o diagnóstico, nossos pacientes foram tratados conservadoramente e, depois de dois anos de evolução, não apresentam mais as lesões.

\section{Referências}

I. APPLE, S. K.; NIEBERG, R.K.; HIRSCHOWITZ, S.L. Fine needle aspiration diagnosis of fibromatosis colli. A report of three cases. Acta cytol, 4 I (suppl. 4): I 373-6, 1997.

2. BLYTHE,W.R. et al. Fibromatosis colli: a common case of neonatal torticollis. Am Fam Physician, 54(6): 1965-7, 1996.

3. GONZALES, J. et al. Congenital torticollis: evaluation by fineneedle aspiration biopsy. Laryngoscope, 99(6 Pt I): 65I-4, 1989.

4.JABER, M. R:; Goldsmith,A.J. Sternocleidomastoid tumor of infancy: two cases of interesting entity. Int J Pediatr Otorhinolaryngol, 47(3): 269-74, 1999.

5. KURTYCZ, D. F. et al. Diagnosis of fibromatosis colli by fine-needle aspiration. Diagn Cytopathol, 23(5): 338-42, 2000.
6. Pereira, S.; Tani, E.; Skoog, L. Diagnosis of fibromatosis colli by fine-needle aspiration (FNA) cytology. Cytopathology, I O(I): 25-9, 1999.

7. RAAB, S. S. et al. Fine needle aspiration biopsy of fibromatosis. Acta Cytol, 37(3): 323-8, 1993.

8.SAUER,T.; SELMER, L.; FRENG,A. Cytologic features of fibromatosis colli of infancy. Acta Cytol, 4 I (3): 633-5, 1997.

9. SCHWARTZ, R.A. et al. Fibromatosis colli. The utility of fine-needle aspiration in diagnosis. Arch Otolariyngol Head Neck Surg, 123(3): 30 I-4, 1997.

I0.WAKELY,P.E. Jr:; PRICE,W. G., FRABLE,W.J.Sternomastoid tumor of infancy (fibromatosis colli): diagnosis by aspiration cytology. Mod Pathol, 2(4): 378-81, 1989

\section{Endereço para correspondência}

Cisele Alborghetti Nai

Laboratório de Anatomia Patológica e Citopatologia da UNOESTE

Rua losé Bongiovani, 700 - Cidade Universitária

CEP 19050-900 - Presidente Prudente-SP

Tel.: (18) 229-1059

Fax: (18) 229-1194

e-mail: patologia@unoeste.br 